\title{
A pilot randomized controlled trial of the feasibility of a self-directed coping skills intervention for couples facing prostate cancer: Rationale and design
}

Sylvie D Lambert ${ }^{1 *}$, Afaf Girgis ${ }^{1}$, Jane Turner ${ }^{2}$, Patrick McElduff' ${ }^{3}$, Karen Kayser ${ }^{4}$ and Paula Vallentine ${ }^{5}$

\begin{abstract}
Background: Although it is known both patients' and partners' reactions to a prostate cancer diagnosis include fear, uncertainty, anxiety and depression, with patients' and partners' reactions mutually determining how they cope with and adjust to the illness, few psychosocial interventions target couples. Those that are available tend to be led by highly trained professionals, limiting their accessibility and long-term sustainability. In addition, it is recognised that patients who might benefit from conventional face-to-face psychosocial interventions do not access these, either by preference or because of geographical or mobility barriers. Self-directed interventions can overcome some of these limitations and have been shown to contribute to patient well-being. This study will examine the feasibility of a self-directed, coping skills intervention for couples affected by cancer, called Coping-Together, and begin to explore its potential impact on couples' illness adjustment. The pilot version of Coping-Together includes a series of four booklets, a DVD, and a relaxation audio CD.
\end{abstract}

Methods/design: In this double-blind, two-group, parallel, randomized controlled trial, 70 couples will be recruited within 4 months of a prostate cancer diagnosis through urology private practices and randomized to:

1) Coping-Together or 2) a minimal ethical care condition. Minimal ethical care condition couples will be mailed information booklets available at the Cancer Council New South Wales and a brochure for the Cancer Council Helpline. The primary outcome (anxiety) and additional secondary outcomes (distress, depression, dyadic adjustment, quality of life, illness or caregiving appraisal, self-efficacy, and dyadic and individual coping) will be assessed at baseline (before receiving study material) and 2 months post-baseline. Intention-to-treat and per protocol analysis will be conducted.

Discussion: As partners' distress rates exceed not only population norms, but also those reported by patients themselves, it is imperative that coping skills interventions target the couple as a unit and enhance both partners ability to overcome cancer challenges. This pilot study will examine the feasibility and potential efficacy of Coping-Together in optimising couples' illness adjustment. This is one of the first feasibility studies to test this innovative coping intervention, which in turn will contribute to the larger literature advocating for psychosocial care of couples affected by prostate cancer.

Trial registration: Australian New Zealand Clinical Trials Registry ACTRN12611000438954

Keywords: Psychosocial adjustment, Couple, Family, Prostate cancer, Stress-coping, Dyadic coping, Anxiety, Intervention, Self-directed, Information resources

\footnotetext{
* Correspondence: s.lambert@unsw.edu.au

${ }^{1}$ Translational Cancer Research Unit, Ingham Institute for Applied Medical Research, South Western Sydney Clinical School, UNSW Medicine, The University of New South Wales, Liverpool, BC NSW 2170, Australia Full list of author information is available at the end of the article
} 
In Australia, cancer is the leading cause of diseaserelated burden (accounting for nearly one-fifth of the total disease burden) [1]. In 2007, 108,368 new cases of cancer were diagnosed in Australia (excluding basal and squamous cell carcinomas of the skin), and slightly more than half of these cases were men [2]. Prostate cancer is the most common type of cancer among men, with 19,403 cases diagnosed in 2007 [2] and 1 in 4 men diagnosed by 85 years of age [3]. Nearly all patients who present with localised prostate cancer will live beyond five years, with the 10- and 15-year survival rates being $93 \%$ and $77 \%$, respectively [4]. As the number of people living beyond initial diagnosis is increasing, so is the time during which the disease sequelae and psychosocial consequences must be managed. Consequently, the focus in practice and research has shifted from viewing cancer as a terminal illness to helping patients and partners learn to cope with cancer demands and optimise functioning and quality of life.

Although treatment for prostate cancer is becoming increasingly successful, the initial diagnosis still comes as a shock [5,6] and resulting treatment often adversely impacts both patients' and partners' quality of life, including their social, psychological, and physical functioning [5-14]. Approximately one third of men diagnosed with prostate cancer report psychological distress [15]. In some contexts, wives of men with prostate cancer have reported as much, if not more, distress than patients [5,9,16]. Although Eton et al. [9] found that men with prostate cancer and their spouses did not differ in terms of general distress; the spouses reported more cancer specific distress than the patients. The concern is that a recent meta-analysis by Hagedoorn et al. [17] found a moderate, positive association between patients' and partners' levels of distress $(\mathrm{r}=.29, \mathrm{p}<.001)$, which implies that patient's high distress has an impact on their partner's illness adjustment (or vice-versa). It follows from this that psychosocial interventions should then target couples [18-20].

The predictors of patient and partner anxiety are typically categorised into three broad classes of variables: demographics, characteristics/stages of disease and treatment, and psychosocial $[12,13,21,22]$. Amongst psychosocial variables, coping is arguably one of the most frequently studied predictors of patient and partner anxiety $[12,13,23]$. Although findings remain equivocal, most studies support that coping strategies directed toward active engagement with the stressor, including both problem- and emotion-focused coping, are associated with more positive adjustment [24]. In contrast, those considered less functional, such as avoidance, behavioural disengagement or denial, are associated with higher levels of distress $[12,13,22,25,26]$. Beyond individual approaches to coping, recent studies have examined the impact of each partner's way of coping on the other's stress (i.e., dyadic coping) and suggest that illness adjustment is enhanced when patients and partners are mutually responsive to each other's stress, view the cancer challenges as "our" problem or "being in it together", and are engaged in collaborative dyadic coping by pooling their resources and problem-solving jointly $[27,28]$. This evidence suggests that a couple-based intervention focused on maximising use of individual and dyadic adaptive coping skills might be most promising in reducing the psychological distress of patients and partners in response to a stressful situation like cancer [21].

Recently, reviews of couple-based interventions suggest that these have the potential to be as, if not more, efficacious than patient-only interventions in optimising patient adjustment and are more efficacious than usual care in enhancing partners' adjustment [29]. For instance, Scott et al. [30] compared the efficacy of CanCOPE (a couple-based, coping skills training intervention for women diagnosed with breast or gynaecological cancer and their partners) with an individual coping intervention and a medical information only condition. CanCOPE women reported significantly less distress and less avoidance post-intervention than the women in the other two conditions. There was also a trend for CanCOPE partners to report less distress than those in the other conditions. Similarly, Nezu et al. [31] examined the efficacy of a problem-solving therapy (PST) among a mixed sample of patients diagnosed with cancer and included two treatment groups: one in which patients attended the PST alone and another one in which PST was attended with a significant other. Post-PST positive effects on quality of life and distress were similar in the two treatment groups. However, at 6- and 12-month follow-ups, patients participating in PST with their partner reported lower distress than patients who attended the PST alone. In the context of other chronic illnesses, couple-based coping or educational interventions have also been shown to be more efficacious than individual-level interventions in optimising illness adjustment [32].

Whilst couple-based interventions are promising in enhancing couples' illness adjustment, most are delivered by highly trained health professionals [33], limiting their long-term accessibility and sustainability, due to high cost and limited availability of qualified professionals, especially in non-metropolitan areas. In addition, it is recognised that patients who might benefit from conventional face-to-face psychosocial interventions do not access these, either by preference or because of geographical or mobility barriers [34,35]. Studies have found that as few as $14 \%$ of distressed patients with cancer accept referral to psychosocial services [36]. Thus, the challenge is to develop a cost-effective couple-based 
intervention that is accessible, sustainable, and efficacious. One suggestion for developing a cost-effective approach to psychosocial interventions involves using a group format instead of an individual format [37]. However, research supporting the feasibility and efficacy of group interventions over individual ones remains equivocal $[37,38]$. Another suggestion for cost containment is the use of a self-directed (also referred to as self-help or self-administered) format [39].

Self-directed interventions overcome some of the barriers of face-to-face services and have several potential advantages for couples, including the choice of selecting what, when, and how they want to learn. In the general psychology literature, unguided, self-help interventions, either print- or computer-based, have been shown to enhance individual well-being, including decreasing anxiety and depression symptoms $[40,41]$. The few self-directed, coping skills interventions developed for individuals facing cancer have been found to be acceptable [42,43], efficacious in enhancing patient well-being [39,42], particularly among distressed individuals [44], and costeffective [39]. In a feasibility study by Alison et al. [43], when patients were questioned about their preferred format for a coping skills intervention, 5\% selected the group format, $56 \%$ selected the one-on-one format, and $39 \%$ selected the self-directed format. Interestingly, more men chose the self-directed format. Beatty et al. [42] recently found support for the efficacy of a self-directed, coping skills workbook for women with breast cancer in improving post-traumatic stress disorder symptoms, cognitive avoidance, and helplessness/hopelessness. The workbook contained information on common medical and psychosocial issues, cognitive behaviour therapybased worksheets to enable active engagement and processing of these issues, and survivors' stories. Interestingly, Krischer, $\mathrm{Xu}$ \& Jacobsen [44] examined the efficacy of a self-administered stress management training intervention among individuals undergoing radiotherapy, including men diagnosed with prostate cancer, and found that distressed individuals benefited more from the self-administered intervention (improvements in mental health and decreased depressive symptoms) than non-distressed individuals. In another context, Dalal et al. [45] found that a self-directed manual was as effective as hospital-based rehabilitation for patients after myocardial infarction in increasing quality of life and reducing total cholesterol levels. The main limitation of the aforementioned self-directed interventions is the exclusive focus on patients, neglecting partners.

Hence, our team has recently developed a self-directed coping skills training intervention for couples affected by cancer, called Coping-Together. This pilot study will examine the feasibility of Coping-Together and begin to explore its potential impact on couples' illness adjustment. For the purpose of the pilot study, the following Coping-Together materials will be included: four booklets, a DVD featuring 'communicating effectively with health care professionals' and a relaxation audio CD.

\section{The Coping-Together intervention}

\section{Theoretical and empirical underpinnings}

Coping-Together is a novel, evidence-based, self-directed psychosocial intervention to help couples develop adaptive, individual and dyadic coping skills and feel more confident in applying these to their current situation. Coping-Together builds on three main theoretical frameworks: 1) Lazarus \& Folkman's stress and coping framework [46], 2) Bodenmann's framework of dyadic coping [47], and 3) Bandura's self-efficacy theory [48].

Of the various coping with stress frameworks, the Lazarus \& Folkman framework is the best known and most widely used in the study of stress caused by cancer. This framework explains that the coping process is initiated in response to the individual's appraisal that important goals have been harmed, lost, or threatened [23]. Coping is typically characterised either as problemfocused coping (alter the stressful situation using strategies such as information-seeking, planning and problem-solving) or emotion-focused coping (regulate situation-related emotions using strategies such as positive reappraisal and behavioural disengagement) [23]. These coping styles are often further considered for their adaptive (e.g., positive reappraisal) versus maladaptive (e.g., denial) nature. The assumption is that if individuals use adaptive coping and are able to regain a sense of control over cancer challenges, they are then less likely to experience distress. In this sense, coping is not only a valuable explanatory concept regarding variability in response to stress, it can also serve as a portal for intervention (i.e., when adaptive coping skills are known, they can then be learnt). Although coping strategies may address and resolve the stressor, in some instances, such as a life-threatening illness like cancer, a favourable resolution might not be possible. At this point, the revised Lazarus \& Folkman framework [46] proposes that coping then focuses on fostering positive emotions despite the presence of negative feelings engendered by the unresolved stressor. Considerable empirical evidence supports the variables postulated by this framework among individuals diagnosed with cancer and their partners [49-51]. Therefore, this framework provides a strong conceptual basis for Coping-Together. Coping-Together is expected to provide couples with the resources needed to manage physical and psychosocial cancer challenges that can be addressed directly, whereas for those stressors that cannot be immediately resolved, CopingTogether sustains meaning-based coping and fosters 
positive emotions. How the content of the Coping-Together intervention is expected to enhance the coping process is further depicted in Figure 1.

Despite the strengths of the Lazarus and Folkman framework, it mainly centers on the individual and the fundamental role that partners play is not explicit. Bodenmann's framework of dyadic coping [47] extends Lazarus and Folkman's framework by acknowledging the reciprocal nature of stress and coping within couples. This framework has been most frequently applied within the marital counselling literature, though it is becoming more popular within the cancer literature [52,53]. Broadly speaking, Bodenmann suggests two dyadic coping styles: positive dyadic coping (e.g., supportive communication; joint problem-solving) and negative dyadic coping (e.g., minimising partner concerns; sarcasm, mocking of concerns). Badr and colleagues [52] found that among couples coping with metastatic breast cancer, the use of positive dyadic coping was associated with greater adjustment than the use of negative dyadic coping.

Bandura's self-efficacy theory posits that people are likely to engage in activities to the extent that they perceive themselves to be competent at those activities [48]. According to Bandura, there are four major sources of self-efficacy: 1) performing a task successfully (mastery experiences), 2) witnessing other people, especially those similar to oneself, successfully complete a task (vicarious experiences), 3) being persuaded that they have the skills and capabilities to succeed (e.g., getting verbal encouragement from others to overcome self-doubt), and 4) addressing psychological responses that impact how a person feels about their abilities in a particular situation [54]. To address these sources of self-efficacy, the Coping-Together booklets provide step-by-step, practical guides to implement the coping strategies proposed, behaviour therapy-based worksheets to encourage selfreflection, and active learning, and quotes reporting patients' and partners' success with the proposed coping strategies.

\section{Content}

Coping-Together takes on a holistic approach to coping with cancer by including strategies to manage physical, social, psychological, and existential cancer-related challenges. The pilot version of Coping-Together includes a series of four booklets developed and qualitatively evaluated by the research team between 2009-2012 [55]. Each booklet addresses one of the following challenges and presents a range of coping strategies shown to be efficacious in managing these: 1) symptom management, 2) couples communicating effectively with health care professionals, 3) supporting each other, and 4) managing worries and emotions. Most available cancer information resources provide information on 'What is cancer' and what couples should or need to do, but the Coping-Together booklets provide information on 'How' couples can go about managing cancer challenges [34]. Multiple coping strategies are presented to couples to facilitate a personalised approach, where couples can 'pick and choose' and apply those that most closely correspond to

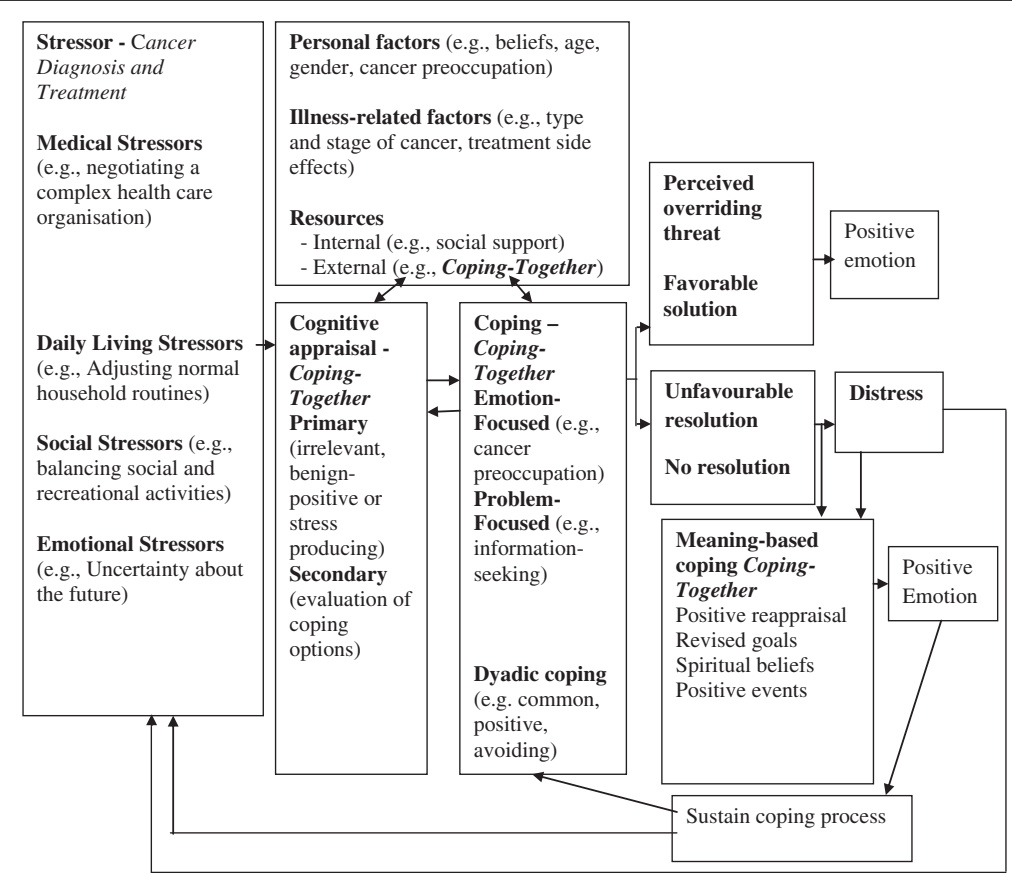

Figure 1 How the Coping-Together intervention can enhance the coping process. 
their needs. Also, the booklets contain information about additional health care resources. For this pilot, the Coping-Together booklets are complemented by electronic media, including a relaxation $\mathrm{CD}$ and a 'Communicating effectively with health care professionals' DVD. Participants will be able to use any or all of these resources at their own discretion and pace prior to collection of the outcome data, which will be 2 months following baseline measurements.

\section{Study aims and hypotheses}

The overall study aims are to 1) examine the acceptability of the methods (e.g., recruitment, survey) to couples affected by prostate cancer and test the feasibility of providing Coping-Together and 2) collect preliminary data to investigate the short-term efficacy of Coping-Together on couples' well-being. The study has two arms: 1) Coping-Together intervention arm and 2) Minimal Ethical Care (MEC) arm.

As this is a pilot study, it is not expected that there will be any significant statistical difference between the Coping-Together and MEC groups on primary and secondary outcomes. However, it is hypothesised that trends will be noted where Coping-Together couples will experience less anxiety (primary hypothesis), cancer specific distress and depression and more positive illness or care giving appraisal, self-efficacy, quality of life (QOL), relationship satisfaction and positive individual and dyadic coping (secondary hypotheses) at 2 months postbaseline compared to MEC couples.

\section{Methods/design}

\section{Design}

The proposed study is a multicentre, stratified, doubleblind, two-group, parallel, randomized controlled trial to compare Coping-Together to MEC. The design of this study was guided by the Medical Research Council framework for developing and evaluating complex interventions [56] and the CONSORT statement [57].

\section{Sample}

Based on other psycho-oncology feasibility studies [43,58,59] and suggestions by Hertzog [60], 35 couples/ group will be recruited for this pilot.

\section{Inclusion and exclusion criteria}

Men diagnosed in the past 4 months with a primary, early-stage, prostate cancer, receiving or planning to receive treatment (including active surveillance), and their partner (spouse, boy/girlfriend, or de facto) will be invited to participate in the study. Additional inclusion criteria will be either the patient or their partner is identified by the Distress Thermometer (DT) as distressed (i.e., score of four or more) at the time of recruitment
[36] and both need to be sufficiently fluent in English and cognitively able to complete surveys. Patient and partner consents are required for the couple to participate in this trial. As Coping-Together was designed to bring about change in how couple cope with cancer challenges and decrease anxiety, couple will be targeted soon after diagnosis, a time typically marked by many concerns and needs [61,62]. Moreover, as it is now wellrecognised that ignoring patients' or partners' baseline distress can undermine the efficacy of an intervention (given the potential for floor effect) [63], distressed patients or partners are included in this study.

\section{Procedures}

It is anticipated that most eligible men will be recruited through urologists' private practices in Australia (New South Wales and South Australia). Weekly, urologists will identify patients meeting the medical (recent, primary, early-stage prostate cancer diagnosis and receiving/planning to receive treatment) and English fluency inclusion criteria. At their next appointment, interested patients will be invited to meet with the on-site research assistant to further discuss study participation and obtain a score on the DT. The research assistant will give interested and eligible participants a study package, which includes an information statement, a consent form, baseline survey, and a study pack to pass on to their partner. The team will follow-up one to two weeks later with non-responders. If the on-site research assistant is not present in the clinic, the urologists will give interested patients study information and obtain verbal consent for a member of the team to contact them within the following week. The study will also be advertised through a range of media outlets, including radio, print, and online channels. It is anticipated that 370 patients will be approached to recruit the target sample size, assuming that $35 \%$ of patients or partners score four or more on the DT [64]; of those, $25 \%$ of couples will be ineligible, $30 \%$ will refuse participation, and $7 \%$ will be lost to follow-up [65]. This study has been approved by the University of Newcastle and the University New South Wales Human Research Ethics Committees.

\section{Randomization of group assignment}

A computer-generated, randomization schedule with block lengths of variable size ( 4 and 6 couples) and stratified by recruitment source will be accessible to the main research assistant to allow assignment of a unique study ID to each couple as their consent forms/baseline surveys are received. Block randomisation is used to achieve balance in the allocation of couples across the MEC and Coping-Together groups and varying the block 
size reduces the chance of treatment allocation being known [66].

\section{Coping-Together and minimal ethical care (MEC) conditions}

At recruitment, participants will be mailed one of two resources, without knowing which one is the study intervention. Coping-Together couples will receive the intervention material previously described within 2 weeks of returning a baseline survey (see Figure 2 study timeline). One to two weeks thereafter, a member of the research team will phone them to orient them to Coping-Together. The intent of this brief orientation call (anticipated duration $=20$ minutes) will be to ensure participants received the material, provide an overview of the content, and explore intended use of the resource. Couples will then receive, fortnightly, a 'Top Tips' sheet highlighting timely content of the booklets and a follow-up telephone call (anticipated duration $=20$ minutes) from a member of the research team to monitor the use of Coping-Together and other resources and answer questions pertaining to the materials received. Although the calls will be conducted by experienced, trained research assistants, the research assistants will not provide counseling, as they are not registered therapists. A script will be developed to guide the discussion.

As MEC couples also have elevated distress, and to blind participants to group allocation, this study will not employ a 'no treatment' control group. MEC couples will be mailed booklets from the 'Understanding Cancer Series' available at the Cancer Council New South Wales and a Cancer Council Helpline brochure, and will also receive initial and follow-up phone calls, comparable in intent and content to the one described for Coping-Together couples. All phone calls will be audio-recorded and coded to monitor topics discussed across intervention participants and ensure that counselling was not provided.

\section{Blinding}

Participants will be told they will receive one of two information packs, but as they do not know which one is the study intervention and as the study survey and contact with the research team is comparable across groups, they are blinded to whether they are in the MEC or Coping-Together group. The participants will also be blinded to study hypotheses. As it is expected that couples will mainly use Coping-Together at home, the chance of MEC participants being exposed to the intervention is minimal.

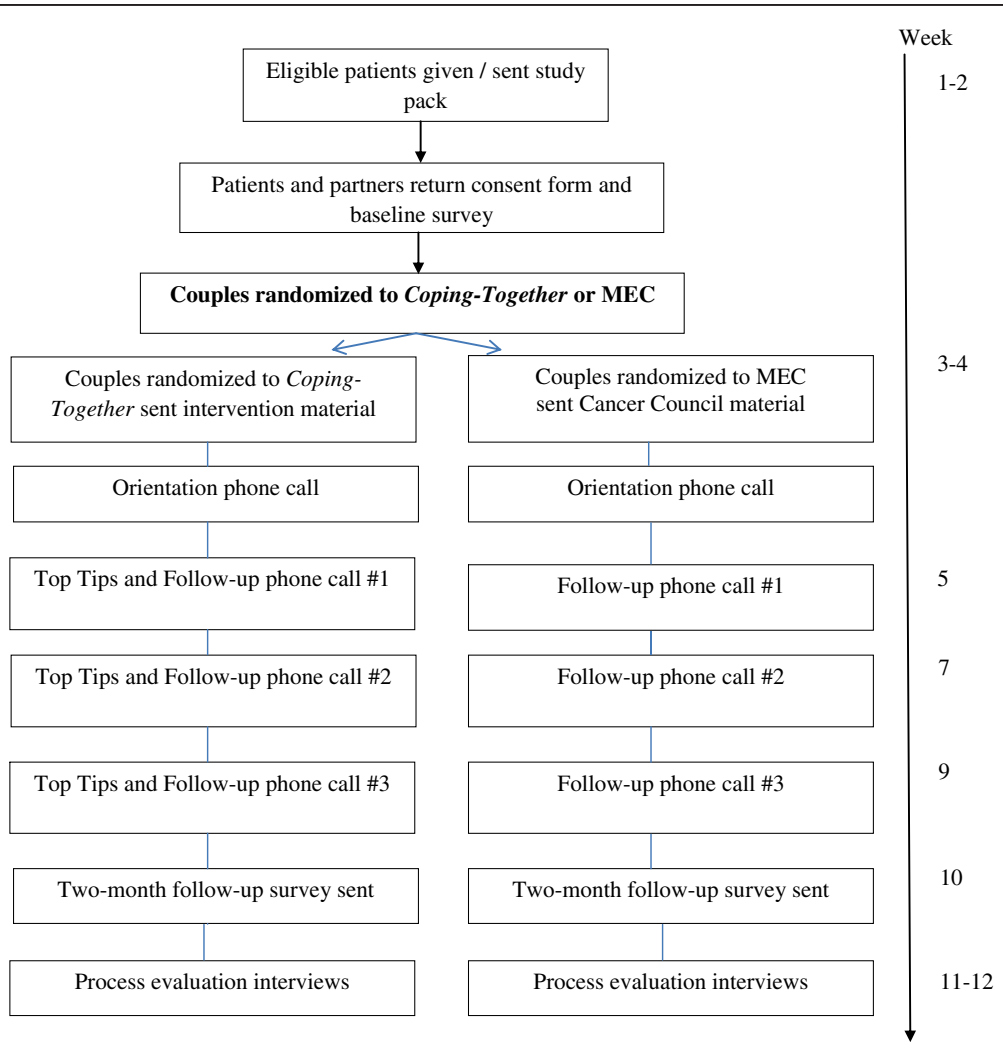

Figure 2 Study Timeline. 
All contact with the couples will occur through the same research assistant(s) who will not be blinded to group allocation and will assign a study ID, randomise participants, send study packs, and conduct follow-up phone calls. A separate research assistant, who will have no contact with participants and will be blinded to group allocation, will enter the data. The chief investigators and the statistician will not be able to link study IDs (and surveys) back to a recruitment site or group and are therefore blinded to group allocation.

\section{Outcomes}

As the development of Coping-Together was guided by the Lazarus \& Folkman's Stress and Coping framework (see Figure 1) [67], outcomes selected either characterise the coping process (appraisal, dyadic and individual coping strategies, and self-efficacy) or indicate the extent to which the coping process was successful in addressing stressors (anxiety, cancer distress, depression, quality of life, and relationship satisfaction).

\section{Measures}

Table 1 lists the primary and secondary outcomes and corresponding measures.

Initial distress screening: At the time of recruitment, the single-item DT will be used to screen patients' level of distress. The DT asks patients to circle the number that best describes their overall distress using a visual analogue scale ranging from $0=$ 'no distress' to $10=$ 'extreme distress' [36]. The DT has convergent validity with the Hospital Anxiety and Depression Scale (HADS) [36], with a cut-off point of four typically resulting in optimal sensitivity and specificity [68].

Primary outcome: Anxiety is the primary outcome, as Coping-Together focuses on coping strategies to manage high levels of anxiety directly and/or cope with cancer demands known to trigger anxiety. Anxiety will be measured using the 7-item anxiety subscale of the Hospital Anxiety and Depression Scale (HADS-A) [69]. HADS-A is a reliable and valid measure of the severity of anxiety for patients with cancer and their partners and is often considered the 'benchmark' for validation of other anxiety measures [87-90].

\section{Secondary outcomes}

Depression will be measured using the 7-item depression subscale of the Hospital Anxiety and Depression Scale (HADS-D) [69].

Cancer specific distress will be measured with the Revised Impact of Event Scale [71].

Quality of Life (QOL) will be measured with the Assessment of Quality of Life - 8 dimensions (AQoL-8D). The AQoL8D is a newly developed health-related QOL instrument specifically for use with people with mental health problems and distress [72]. Also, the Caregiver's QOL Index-Cancer will be used to assess caregiver's mental and emotional burden, life disruption, positive adaptation and financial concerns [73].

Relationship satisfaction for partners and caregivers will be measured using the Spanier Dyadic Adjustment Scale (dyadic consensus, satisfaction, cohesion, and affective expression) [74], which is a widely used measure of satisfaction with intimate relationships.

Primary illness appraisal will be measured by the Kessler's Cognitive Appraisal of Health Scale [76], Mishel's Uncertainty in Illness Scale [77], and the Caregiving Illness Appraisal Scale [78,79].

Secondary illness appraisal (self-efficacy) will be measured by the Cancer Self-Efficacy Scale [78] and the Communication and Attitudinal Self-Efficacy Scale for Cancer (CASE-Cancer) [80].

Individual and dyadic coping will be measured by the Brief COPE [82] and the Dyadic Coping Inventory [81].

\section{Moderators}

Although this pilot is underpowered to examine the differential impact of the intervention across participant sub-groups, the pilot survey will include all measures that would potentially be considered for a larger trial to comprehensively examine the feasibility of the methods.

Information obtained and information-seeking preferences will be measured by the EORTC Quality of Life (QOL) - information module [83] and a tool developed by the first author - The Profile of Preferences for Cancer Information (PPCI) [84,91], respectively.

A cancer care diary developed by members of the research team will also be completed for the duration of the study to document health professionals seen and health care resources utilised.

Readiness for self-directed learning will be measured by items adapted from Guglielmino's Learning Preference Scale [85].

Problems experienced will be measured by items adapted from the SupportScreen scale [86].

Socio-demographic, disease and medical variables, including date of diagnosis, treatment, symptom distress [92], age, and education, will also be measured.

\section{Data analysis}

Intention-to-treat and per protocol analysis will be conducted separately for patients and partners. The primary outcome, anxiety (HADS-A) two months post baseline, will be analysed using ANalysis of COVAriance (ANCOVA). The main predictor variable in the ANCOVA model will be treatment group, and the participants' baseline score will be included as a covariate. ANCOVA will also be used to explore the secondary 
Table 1 Coping-Together study outcomes and measures

\begin{tabular}{|c|c|}
\hline Outcomes & Measures and Psychometrics \\
\hline \multicolumn{2}{|r|}{ Primary Outcome } \\
\hline Anxiety & 7-item HADS-Anxiety Subscale (patients and partners) [69] ( $a=.68-.93)$ [70] \\
\hline \multicolumn{2}{|r|}{ Secondary Outcomes } \\
\hline Depression & 7-item HADS-Depression Subscale (patients and partners) [69] ( $a=.67-.90)[70]$ \\
\hline Cancer distress & 15-item Revised Impact of Event Scale (patients and partners; $a=.78-.96)[71]$ \\
\hline \multirow[t]{2}{*}{ Quality of Life (QOL) } & 35-item Assessment of Quality of Life - 8 Dimensions Scale (AQoL-8D; patients and partners) [72] \\
\hline & 35-item Caregiver's QOL Index-Cancer (partners) [73] \\
\hline Relationship satisfaction & 7-item Spanier Dyadic Adjustment Scale (patients and partners) [74] a = .89-.95) [75] \\
\hline \multirow[t]{3}{*}{ Appraisal } & 28-item Kessler Cognitive Appraisal of Health Scale (patients and partners [adapted]; $a>.70$ ) [76] \\
\hline & 33-item Mishel's Uncertainty Scale (patients and partners; $a=.64-0.91$ ) [77] \\
\hline & 27-item Appraisal of Caregiving Scale (partners; $a>.85$ ) $[78,79]$ \\
\hline \multirow[t]{2}{*}{ Self-efficacy } & 17-item Cancer Self-Efficacy Scale (patients and partners; $a=.97$ ) [78] \\
\hline & $\begin{array}{l}\text { 12-item Communication and Attitudinal Self-Efficacy Scale for Cancer (CASE-Cancer; patients and } \\
\text { partners [adapted]; } a=.76-.77) \text { [80] }\end{array}$ \\
\hline Dyadic coping & 37-item Dyadic Coping Inventory (patients and partners; $a=.63-84$ ) [81] \\
\hline Individual Coping & $\begin{array}{l}\text { 28-item Brief COPE measures } 14 \text { individual-level coping strategies (patients and partners; } a=.60-.90 \text { ) } \\
\text { [82] }\end{array}$ \\
\hline \multicolumn{2}{|r|}{ Moderators* } \\
\hline \multirow{2}{*}{$\begin{array}{l}\text { Information obtained and information- } \\
\text { seeking preferences }\end{array}$} & 25-item EORTC Quality of Life (QOL) - information module (patients and partners; $a>0.70$ ) [83] \\
\hline & 45-item Profile of Preferences for Cancer Information (PPCI) (patients and partners [adapted]) [84] \\
\hline Readiness for self-directed learning & 39-item adapted version of the Learning Preference Scale (patients and partners [adapted]) [85] \\
\hline Problems experienced & 48-item adapted version of SupportScreen scale (patients and partners [adapted]) [86] \\
\hline
\end{tabular}

outcome measures. Questionnaires measuring potential moderators were included in the survey to reflect those that would be included in a survey for a larger trial; however, the pilot is underpowered and moderators will not be analysed.

\section{Process evaluation}

Process evaluation will explore the intervention's implementation and receipt [93]. Following their last data collection point, a process evaluation, semi-structured phone interview will be scheduled with consenting Coping-Together and MEC couples (consent obtained at baseline) to explore their views on, and opinions about, the Coping-Together or MEC material used and obtain feedback on the study's process and procedures. Interviews will be audio-recorded and transcribed verbatim. For consistency, a couple's process evaluation interview will be completed by the same research assistant that conducted their follow-up phone calls. The interview is anticipated to last 45-60 minutes. A script will be used to open and focus the discussion and prompts will be specified to help the interviewers to further elaborate on the study's topics, if needed. All transcripts will be reviewed line-by-line and words, statements, or paragraphs pertaining to participants' opinions about the Coping-Together or MEC material or the study will be coded. Interpretation and clustering of the codes will result in detecting themes and patterns. Transcripts will be coded by two research team members and emerging findings will be discussed at regular team meetings.

\section{Discussion}

Partners' anxiety rates exceed not only the Australian norm, but also those of cancer survivors themselves [5]. Hence, it is imperative that coping skills interventions target the couple as a unit and enhance both patients' and partners' ability to overcome cancer challenges. Recent reviews support the efficacy of coping skills training interventions in optimising patients' illness adjustment $[26,94]$. However, these interventions tend to be led by highly trained health professionals; considerably limiting their long-term sustainability, due to high cost and limited availability of qualified professionals, especially in non-metropolitan areas. In addition, it is recognised that patients who might benefit from conventional face-to-face psychosocial interventions do not access these, either by preference or because of geographical or mobility barriers [34,35]. Self-directed (also referred to as self-help or 
self-administered) interventions overcome these limitations, are acceptable to patients and efficacious in decreasing patients' distress [34]. Coping-Together is a novel psychosocial intervention, as it targets both patients and their partners, translates up-to-date research on effective coping and renders it readily available to couples for their use where and when they need to, and actively engages couples in learning new coping skills. To our knowledge, Coping-Together is the first, self-directed intervention for couples affected by cancer.

\section{Implications}

Coping-Together has the potential to have a direct impact on the psychological well-being of patients and their partners and to redress issues of access and equity for couples from regional, rural and remote areas, without burdening an already stretched oncology workforce. This pilot trial will investigate the feasibility and potential efficacy of Coping-Together in reducing the negative psychosocial impact of prostate cancer on patients and their partners, which in turn will be used to design a larger trial that will not only examine the efficacy of CopingTogether, but also its direct cost and cost-effectiveness. Findings from this study will also contribute to the larger literature in advocating for psychosocial care in the acute post-diagnostic phase and in identifying individual and couple-level factors that contribute to patients' and partners' coping, anxiety, and use of self-directed resources. If future studies support the efficacy of Coping-Together, the intervention's low production cost and self-directed nature will contribute to its ready integration into existing supportive care infrastructures for patients diagnosed with prostate cancer and their partners.

\section{Abbreviations}

NHMRC: National Health and Medical Research Council; PST: Problem-solving therapy; MEC: Minimal ethical care; QOL: Quality of life; DT: Distress Thermometer; HADS: Hospital Anxiety and Depression Scale; AQoL8D: Assessment of Quality of Life -8 dimensions; CASECancer: Communication and Attitudinal Self-Efficacy Scale for cancer scale; PPCI: Profile of Preferences for Cancer Information; ANCOVA: ANalysis of covAriance.

\section{Competing interests}

The authors declare that they have no competing interests.

\section{Authors' contributions}

SL conceived the study, participated in its design, led the development of the Coping-Together resource, and drafted the manuscript. AG, JT, PV and KK participated in the design of this study, provided critical feedback on CopingTogether, and provided feedback on the draft of this manuscript. PM participated in the design of this study and provided feedback on the draft of this manuscript. All authors have read and approved the final manuscript.

\section{Acknowledgement}

The development and evaluation of Coping-Together was supported by the Centre for Health Research and Psycho-oncology, The Priority Research Centre in Health Behaviour, The University of Newcastle, the Clinical Oncological Society of Australia (COSA) and Sanofi-Aventis, and the National Health and Medical Research Council. Dr Lambert is supported by a National Health and Medical Research Council Research Fellowship (APP1012869) and
Prof Girgis by a Cancer Institute New South Wales grant. We would like to thank Ms Hayley Candler, Dr Janelle Levesque, and Mr Tim Regan, for their assistance with this project. We are also grateful to all clinicians and reviewers who have contributed their expertise and time to the development of the Coping-Together booklets, including Dr Jemma Gilchrist, Dr Ben Britton, Dr Catalina Lawsin, Ms Fiona van derPlaat, and Cancer Nurses (Cancer Care Co-ordinators, Breast Care Nurses, Clinical Nurse Consultants) from the Cancer Care Coordination network within the Hunter New England Local Health District. We would also like to thank all clinicians who will be helping us recruit participants for this study.

\section{Author details}

${ }^{1}$ Translational Cancer Research Unit, Ingham Institute for Applied Medical Research, South Western Sydney Clinical School, UNSW Medicine, The University of New South Wales, Liverpool, BC NSW 2170, Australia. ${ }^{2}$ The University of Queensland, Mental Health Centre K Floor, Herston, QLD 4029, Australia. ${ }^{3}$ School of Medicine and Public Health, The University of Newcastle, Hunter Medical Research Institute (HMRI) Building, New Lambton, NSW 2305, Australia. ${ }^{4}$ Kent School of Social Work, University of Louisville, Louisville, KY 40292, USA. ${ }^{5}$ Cancer Council NSW, 153 Dowling Street, Woolloomooloo, NSW 2011, Australia.

Received: 17 April 2012 Accepted: 17 September 2012

Published: 26 September 2012

\section{References}

1. Australian Institute of Health and Welfare (AlHW) \& Australasian Association of Cancer Registries (AACR): Cancer in Australia: an overview, 2008, Cancer series no.46. Cat. no. CAN 42. Canberra: AlHW; 2008.

2. Australian Institute of Health and Welfare \& Australasian Association of Cancer Registries: Cancer in Australia: in brief 2010, Cancer series no. 59. Cat. no. CAN 55. Canberra: AlHW; 2010.

3. Australian Institute of Health and Welfare: Australia's health: Australia's health series no. 12. Cat. no. AUS 122. Canberra: Australian Institute of Health and Welfare; 2010.

4. Prostate Cancer: Prostate Cancer. http://www.cancer.org.au/aboutcancer/ cancertypes/prostatecancer.htm.

5. Resendes $L A, M c C o r k l e ~ R$ : Spousal responses to prostate cancer: an integrative review. Canc Invest 2006, 24:192-198.

6. Lambert SD, Loiselle CG, Macdonald ME: An in-depth exploration of information-seeking behavior among individuals with cancer: part 2 understanding patterns of information disinterest and avoidance. Canc Nurs 2009, 32:26-36.

7. Northouse LL, Mood DW, Montie JE, Sandler HM, Forman JD, Hussain M, Pienta KJ, Smith DC, Sanda MG, Kershaw T: Living with prostate cancer: patients' and spouses' psychosocial status and quality of life. J Clin Oncol 2007, 25:4171-4177.

8. Weber BA, Roberts $L$, Yarandi $H$, Mills $T L$, Chumbler NR, Wajsman Z: The impact of dyadic social support on self-efficacy and depression after radical prostatectomy. J Aging Health 2007, 19:630-645.

9. Eton DT, Lepore SJ, Helgeson VS: Psychological distress in spouses of men treated for early-stage prostate carcinoma. Cancer 2005, 103:2412-2418.

10. Soloway CT, Soloway MS, Kim SS, Kava BR: Sexual, psychological and dyadic qualities of the prostate cancer 'couple'. BJU Int 2005, 95:6.

11. Girgis A, Lambert SD: Caregivers of cancer survivors: the state of the field. Canc Forum 2009, 33:167-171.

12. Lambert SD, Girgis A, Lecathelinais C, Stacey F: Walking a mile in their shoes: anxiety and depression among caregivers of cancer survivors at six and 12 months post-diagnosis. Support Care Canc 2012, Published ahead of print (Jun 3 2012).

13. Lambert SD, Jones B, Girgis A, Lecathelinais C: Distressed partners and caregivers do not recover easily: adjustment trajectories among partners and caregivers of cancer survivors. Ann Behav Med 2012, 2:225-235.

14. Boyes A, Girgis A, D'Este C, Zucca A: Flourishing or floundering? Prevalence and correlates of anxiety and depression among a population-based sample of adult cancer survivors 6 months after diagnosis. J Affect Disord 2011, 135:184-192.

15. Zabora J, BrintzenhofeSzoc K, Curbow B, Hooker C, Plantadosi S: The prevalence of psychological distress by cancer site. Psychooncology 2001, 10:19-28. 
16. Couper J, Bloch S, Love AW, Duchesne G, Macvean M, Kissane DW: The psychosocial impact of prostate cancer on patients and their partners. Med J Aust 2006, 185:428-432.

17. Hagedoom M, Sanderman R, Bolks H, Tuinstra J, Coyne JC: Distress in couples coping with cancer: a meta-analysis and critical review of role and gender effects. Psychol Bull 2008, 134:1-30.

18. Banthia R, Malcarne VL, Varni JW, Ko CM, Sadler GR, Greenbergs HL: The effects of dyadic strength and coping styles on psychological distress in couples faced with prostate cancer. J Behav Med 2003, 26:31-52.

19. Couper JW, Bloch S, Love A, Duchesne G, MacVean M, Kissane D: Coping patterns and psychosocial distress in female partners of prostate cancer patients. Psychosomatics 2009, 50:375-382.

20. Kim Y, Kashy D, Wellisch D, Spillers R, Kaw C, Smith T: Quality of life of couples dealing with cancer: dyadic and individual adjustment among breast and prostate cancer survivors and their spousal caregivers. Ann Behav Med 2008, 35:230-238.

21. National Breast Cancer Centre NCCl: Clinical Practice Guidelines for the Psychosocial Care of Adults with Cancer. Camperdown, NSW: National Breast Cancer Centre; 2003.

22. Meyerowitz BE, Oh S: Psychosocial response to cancer diagnosis and treatment. In Handbook of Cancer Control and Behavioral Science: A Resource for Researchers, Practitioners, and Policymakers. Edited by Miller SM, Bowen DJ, Croyle RT, Rowland JH. Washington, DC: American Psychological Association; 2009:361-389.

23. Folkman S, Moskowitz J: Coping: pitfalls and promise. Ann Rev Psychol 2004, 55:745-774

24. Stanton AL, Danoff-Burg S, Huggins M: The first year after breast cancer diagnosis: hope and coping strategies as predictors of adjustment. Psychooncology 2002, 11:93-102.

25. Ben-Zur H, Gilbar O, Lev S: Coping with breast cancer: patient, spouse, and dyad models. Psychosom Med 2001, 63:32-39.

26. Manne SL: Coping with cancer: findings of research and intervention studies. In Coping with Chronic Illness and Disability. Edited by Martz E, Livneh H. New York: USA: Springer Science+Business Media; 2007:191-293.

27. Kayser K: Enhancing dyadic coping during a time of crisis: A theory-based intervention with breast cancer patients and their partners. In Couples Coping with Stress: Emerging Perspectives on Dyadic Coping. Edited by Revenson TA, Kayser K, Bodenmann G. Washington, DC: American Psychological Association; 2005:175-194.

28. Berg CA, Wiebe DJ, Butner J, Bloor L, Bradstreet C, Upchurch R, Hayes J, Stephenson R, Nail L, Patton C: Collaborative coping and daily mood in couples dealing with prostate cancer. Psychol Aging 2008, 23:505-516.

29. Regan T, Lambert SD, Girgis A, Kelly B, Turner J, Kayser K: Do couple-based interventions make a difference for couples affected by cancer? BMC Canc 2012, 12:279.

30. Scott JL, Halford KW, Ward BG: United we stand? The effects of a couplecoping intervention on adjustment to early stage breast or gynecological cancer. J Consult Clin Psychol 2004, 72:1122-1135.

31. Nezu A, Nezu C, Felgoise S, McClure K, Houts P: Project Genesis: Assessing the efficacy of problem-solving therapy for distressed adult cancer patients. J Consult Clin Psychol 2003, 71:13

32. Martire LM: The "relative" efficacy of involving family in psychosocial interventions for chronic illness: are there added benefits to patients and family members? Fam Syst Health 2005, 23:312-328.

33. Hopkinson JB, Brown JC, Okamoto I, Addington-Hall JM: The effectiveness of patient-family carer (couple) intervention for the management of symptoms and other health-related problems in people affected by cancer: a systematic literature search and narrative review. J Pain Symptom Manage 2012, 43:111-142.

34. Beatty L, Koczwara B, Rice J, Wade T: Evaluating the efficacy of a self-help workbook for women recently diagnosed with breast cancer. Asia Pac $J$ Clin Oncol 2009, 5:A241.

35. Lambert S, Kelly B, Girgis A, Boyes A, Cameron A, Adams C, Proietto A: Self-reliance and perception of psycho-oncology service needs among distressed women with gynaecological cancer. Support Care Canc 2012, 20:s215.

36. Tuinman MA, Gazendam-Donofrio S, Hoekstra-Weebers J: Screening and referral for psychosocial distress in oncologic practice: use of the Distress Thermometer. Cancer 2008, 113:870-878.
37. Edgar L, Rosberger Z, Collet J-P: Lessons learned: outcome and methodology of a coping skills intervention trial comparing individual and group formats for patients with cancer. Int J Psychiatr Med 2001, 31:289-304.

38. Tatrow K, Montgomery GH: Cognitive behavioral therapy techniques for distress and pain in breast cancer patients: a meta-analysis. J Behav Med 2006, 29:17-27.

39. Jacobsen PB, Meade CD, Stein KD, Chirikos TN, Small BJ, Ruckdeschel JC: Efficacy and costs of two forms of stress management training for cancer patients undergoing chemotherapy. J Clin Oncol 2002, 20:2851-2862

40. Gellatly J, Bower P, Hennessy S, Richards D, Gilbody S, Lovell K: What makes self-help interventions effective in the management of depressive symptoms? Meta-analysis and meta-regression. Psychol Med 2007, 37:1217-1228

41. Mains JA, Scogin FR: The effectiveness of self-admisnistered treatments: a practice-friendly review of the research. J Clin Psychol 2003, 59:237-246.

42. Beatty L, Koczwara B, Rice J, Wade T: A randomised controlled trial to evaluate the effects of a self-help workbook intervention on distress, coping and QOL after breast cancer diagnosis. Med J Aust 2010, 193(5 Suppl):S68-S73.

43. Allison P, Edgar L, Nicolau B, Archer J, Black M, et al: Results of a feasibility study for a psycho-educational intervention in head and neck cancer. Psychooncology 2004, 13:482-485.

44. Krischer MM, Xu P, Meade CD, Jacobsen PB: Self-administered stress management training in patients undergoing radiotherapy. J Clin Oncol 2007, 25:4657-4662.

45. Dalal H, Evans P, Campbell J, Taylor R, Watt A, et al: Home-based versus hospital-based rehabilitation after myocardinal infraction: a randomised trial with preference arms - Cornwall Heart Attack Rehabilitation Management Study (CHARMS). Int J Cardiol 2007, 119:202-211.

46. Folkman S: Positive psychological states and coping with severe stress. Soc Sci Med 1997, 45:1207-1221.

47. Bodenmann G: A systemic-transactional conceptualization of stress and coping in couples. Swiss J Psychol Schweiz Z Psychol Rev Suisse Psychol 1995, 54:34-49.

48. Bandura A: Social Foundations of Thought and Action: a Social Cognitive Theory. NJ: Prentice-Hall, Englewood Cliffs; 1986.

49. Kershaw T, Mood D, Newth G, Ronis DL, Sanda MG, Vaishampayan U, Northouse L: Longitudinal analysis of a model to predict quality of life in prostate cancer patients and their spouses. Ann Behav Med 2008, 36:117-128.

50. Northouse L, Templin T, Mood D: Couples' adjustment to breast disease during the first year following diagnosis. J Behav Med 2001, 24:115-136.

51. Northouse LL, Mood D, Templin T, Mellon S, George T: Couples' patterns of adjustment to colon cancer. Soc Sci Med 2000, 50:271-284

52. Badr H, Carmack CL, Kashy DA, Cristofanilli M, Revenson TA: Dyadic coping in metastatic breast cancer. Health Psychol 2010, 29:169-180.

53. Kayser K, Feldman BN, Borstelmann NA, Daniels AA: Effects of a randomized couple-based intervention on quality of life of breast cancer patients and their partners. Soc Work Res 2010, 34:20-32.

54. Bandura A: Self-efficacy,Encyclopedia of Human Behavior, Volume 4. New York: Academic; 1994:71-81 Ramachaudran VS (Series Editor): Encyclopedia of human behavior.

55. Lambert S, Girgis A, Chambers SK, Sundquist K: Coping-Together: development and pilot testing of a self-directed coping skills intervention for patients-primary support person dyads. Psychooncology 2010, 19:\$259.

56. Developing and evaluating complex interventions: new guidance. www.mrc.ac. uk/complexinterventionsguidance.

57. Altman D, Schulz K, Moher D, Egger M, Davidoff F, Elbourne D, Gøtzsche PC, Lang T, CONSORT GROUP (Consolidated Standards of Reporting Trials): The revised CONSORT statement for reporting randomized trials: explanation and elaboration. Ann Intern Med 2001, 134:663-694.

58. Lounsberry JJ, MacRae H, Angen M, Hoeber M, Carlson LE: Feasibility study of a telehealth delivered, psychoeducational support group for allogeneic hematopoietic stem cell transplant patients. Psychooncology 2010, 19:777-781.

59. Hawkes AL, Gollschewski S, Lynch BM, Chambers S: A telephone-delivered lifestyle intervention for colorectal cancer survivors 'CanChange': a pilot study. Psychooncology 2009, 18:449-455. 
60. Hertzog MA: Considerations in determining sample size for pilot studies. Res Nurs Health 2008, 31:180-191.

61. Kayser K, Scott JL: Helping couples cope with women's cancers: an evidencebased approach for practitioners. New York: Springer Science + Business Media; 2008.

62. Millar K, Purushotham A, McLatchie E, George W, Murray G: A 1-year prospective study of individual variation in distress, and illness perceptions, after treatment for breast cancer. J Psychosom Res 2005, 58:335-342.

63. Linden W, Satin JR: Avoidable pitfalls in behavioral medicine outcome research. Ann Behav Med 2007, 33:143-147.

64. Carlson LE, Angen M, Cullum J, Goodey E, Koopmans J, Lamont L, MacRae $J \mathrm{H}$, Martin M, Pelletier G, Robinson J, et al: High levels of untreated distress and fatigue in cancer patients. Br J Cancer 2004, 90:2297-2304.

65. Harden J, Falahee M, Bickes J, Schafenacker A, Walker J, Mood D, Northouse LL: Factors associated with prostate cancer patients' and their spouses' satisfaction with a family-based intervention. Canc Nurs 2009, 32:482-492.

66. Schulz KF, Grimes DA: Generation of allocation sequences in randomised trials: chance, not choice. Lancet 2002, 359:515-519.

67. Lazarus R, Folkman S: Stress, appraisal, and coping. New York: Springer Publishing Company Inc; 1984.

68. Jacobsen PB, Donovan KA, Trask PC, Fleishman SB, Zabora J, Baker F, Holland JC: Screening for psychologic distress in ambulatory cancer patients: a multicenter evaluation of the distress thermometer. Cancer 2005, 103:1494-1502.

69. Zigmond AS, Snaith RP: The Hospital Anxiety and Depression Scale. Acta Psychiatr Scand 1983, 67:361-370.

70. Bjelland I, Dahl A, Haug T, Neckelmann D: The validity of the Hospital Anxiety and Depression Scale: an updated literature review. J Psychosom Res 2002, 52:69-77.

71. Weiss DS, Marmar CR: The Impact of Event Scale - revised. In Assessing psychological trauma and PTSD. Edited by Wilson JP, Keane TM. New York: Guilford Press; 1997:399-411.

72. Richardson J, Khan M, lezzi A, Sinha K, Mihalopoulos C, Herrman H, Hawthorne G, Schweitzer I: The AQoL-8D (PsyQoL) MAU Instrument: overview September 2009 Research paper39, Centre for Health Economics; 2009.

73. Weitzner MA, Jacobsen PB, Wagner H, Friedland J, Cox C: The Caregiver Quality of Life Index-Cancer (CQOLC) scale: development and validation of an instrument to measure quality of life of the family caregiver of patients with cancer. Qual Life Res 1999, 8:55-63.

74. Spanier GB: Measuring dyadic adjustment: new scales for assessing the quality of marriage and similar dyads. J Marriage Fam 1976, 38:15-28.

75. Manne SL, Norton TR, Ostroff JS, Winkel G, Fox K, Grana G: Protective buffering and psychological distress among couples coping with breast cancer: the moderating role of relationship satisfaction. J Fam Psychol 2007, 21:380-388.

76. Kessler TA: The Cognitive Appraisal of Health Scale: development of psychometric evaluation. Res Nurs Health 1998, 21:73-82.

77. Mishel MH: The measurement of uncertainty in illness. Nurs Res 1981, 30:258-263.

78. Northouse LL, Mood DW, Schafenacker A, Montie JE, Sandler SM, Forman JD, Hussain H, Pienta KJ, Smith DC, Kershaw T: Randomized clinical trial of a family intervention for prostate cancer patients and their spouses. Cancer 2007, 110:2809-2818.

79. Northouse L, Kershaw T, Mood D, Schafenacker A: Effects of a family intervention on the quality of life of women with recurrent breast cancer and their family caregivers. Psychooncology 2005, 14:478-491.

80. Wolf MS, Chang $C H$, Davis T, Makoul G: Development and validation of the Communication and Attitudinal Self-Efficacy scale for cancer (CASE-cancer). Patient Educ Couns 2005, 57:333-341.

81. Feldman BN, Broussard CA: The influence of relational factors on men's adjustment to their partners' newly-diagnosed breast cancer. J Psychosoc Oncol 2005, 23:23-43.

82. Carver CS: You want to measure coping but your protocol's too long: consider the Brief COPE. Int J Behav Med 1997, 4:92-100

83. Arraras Jl, Greimel E, Sezer O, Chie W-C, Bergenmar M, Costantini A, Young T, Vlasic KK, Velikova G: An international validation study of the EORTC QLQ-INFO25 questionnaire: an instrument to assess the information given to cancer patients. Eur J Cancer 2010, 46:2726-2738.
84. Lambert S, Loiselle C: Multi-phase development of the Profile of Preferences for Cancer Information scale: Challenges and promises. Asia Pac J Clin Oncol 2009, 5:A249.

85. Guglielmino LM: Development of the Self-Directed Learning Readiness Scale. Diss Abstr Int 1977, 38:6467.

86. Loscalzo M, Clark K, Dillehunt J, Rinehart R, Strowbridge R, Smith D: SupportScreen: a model for improving patient outcomes. J Natl Compr Canc Netw 2010, 8:496-504.

87. Carlson LE, Bultz BD: Cancer distress screening - needs, models, and methods. J Psychosom Res 2003, 55:403-409.

88. Schneider S, Moyer A, Knapp-Oliver S, Sohl S, Cannella D, Targhetta V: Pre-intervention distress moderates the efficacy of psychosocial treatment for cancer patients: a meta-analysis. J Behav Med 2009, 33:1-14.

89. Luckett T, Butow PN, King MT, Oguchi M, Heading G, Hackl NA, Rankin N, Price MA: A review and recommendations for optimal outcome measures of anxiety, depression and general distress in studies evaluating psychosocial interventions for English-speaking adults with heterogeneous cancer diagnoses. Support Care Canc 2010, 18:1241-1262.

90. Lambert S, Pallant JF, Boyes A, King M, Britton B, Girgis A: A Rasch analysis of alternative structures of the HADS among cancer survivors. Psychooncology 2012, 20:919-925.

91. Loiselle CG DLS: Theoretical and evidence-based development of the Profile of Preferences for Cancer Information Scale. Psychooncology 2009, 18(Suppl. 2):S74

92. Portenoy RK, Thaler HT, Kornblith AB, Lepore JM, Friedlander-Klar H, Kiyasu E, Sobel K, Coyle N, Kemeny N, Norton L, et al: The Memorial Symptom Assessment Scale: an instrument for the evaluation of symptom prevalence, characteristics and distress. Eur J Cancer 1994, 30A:1326-1336.

93. Oakley A, Strange V, Bonell C, Allen E, Stephenson J: Process evaluation in randomised control trials of complex interventions. BMJ 2006, 332:413-416.

94. Osborn RL, Demoncada AC, Feuerstein M: Psychosocial interventions for depression, anxiety, and quality of life in cancer survivors: meta-analyses. Int J Psychiatr Med 2006, 36:13-34.

doi:10.1186/1477-7525-10-119

Cite this article as: Lambert et al:: A pilot randomized controlled trial of the feasibility of a self-directed coping skills intervention for couples facing prostate cancer: Rationale and design. Health and Quality of Life Outcomes 2012 10:119.

\section{Submit your next manuscript to BioMed Central and take full advantage of:}

- Convenient online submission

- Thorough peer review

- No space constraints or color figure charges

- Immediate publication on acceptance

- Inclusion in PubMed, CAS, Scopus and Google Scholar

- Research which is freely available for redistribution 